\title{
Jejunum and Ileum Neuroendocrine Tumor pN0 TNM Finding v8
}

National Cancer Institute

\section{Source}

National Cancer Institute. Lejunum and Ileum Neuroendocrine Tumor pNO TNM Finding v8. NCI Thesaurus. Code C135116.

Jejunum and ileum neuroendocrine tumor without regional lymph node metastasis. (from AJCC 8th Ed.) 